\title{
Prevalence of diarrhea causing protozoan infections and associated risk factors in diarrheic under five children in Bahir Dar town, northwest Ethiopia: pediatric clinic based study
}

\author{
Ibrahim Mohammed ${ }^{1}$, Endalkachew Nibret ${ }^{1 *}$, Mulugeta Kibret ${ }^{1}$, Bayeh Abera $^{2}$, Melaku Adal ${ }^{1}$ \\ ${ }^{1}$ Department of Biology, Science College, Bahir Dar University, Ethiopia. \\ ${ }^{2}$ Department of Microbiology, Immunology and Parasitology, College of Medicine and Health Sciences, Bahir Dar \\ University, Ethiopia
}

\begin{abstract}
Diarrheal diseases cause about 3 million deaths annually, mainly to children under five years of age. This study determined the prevalence of diarrhea causing intestinal protozoans and the associated risk factors in diarrheic children aged below five years in Bahir Dar town, Ethiopia. From November 2011 to February 2012, pediatric clinic based study was conducted. Stool specimens were collected from 422 diarrheic children using labeled stool cups and examined microscopically for the presence of cysts, trophozoites, and oocysts. Direct saline, formalin-ether concentration, and modified Ziehl-Neelson staining methods were used for stool examination. Eighty six (20.4\%) of the stool samples had one or more intestinal protozoan parasites. Prevalence of Entamoeba histolytica/dispar was $15.2 \%$ (64/422). Cryptosporidium spp., and Giardia intestinalis were detected as single infections in $16(3.8 \%)$, and four $(0.9 \%)$ of the study subjects, respectively. A relatively high prevalence of protozoal infection was recorded and therefore public health education about diarrhea causing protozoans and potential risk factors for diarrhea should be given to caretakers/parents for prevention and control of diarrhea under five children.
\end{abstract}

Keywords: Cryptosporidium, Diarrhea, E. histolytica/dispar, G. intestinalis, Prevalence, Risk factors

DOI: $\underline{\text { http://dx.doi.org/10.4314/ejst.v9i1.2 }}$

\section{INTRODUCTION}

Diarrhea remains a leading cause of mortality among children under five years of age around the world (Black et al., 2010). Globally, 1.3 billion cases of acute diarrhea occur in children below five years annually, of which more than 3 million cases are fatal; $80 \%$ of these deaths occurred in children below two years of age (Samal et al., 2008). The WHO (2004) ranks diarrheal disease as the second most common cause of morbidity and mortality in children of the developing world following acute respiratory infections.

In developing countries, diarrheal disease kills 1.5 million children under the age of five years every year (Elias, 2008). In Africa each child experiences five episodes of diarrhea per year and 800,000 children die each year from diarrhea and dehydration (WHO, 1996). The Ethiopian Demographic and Health Survey (EDHS) conducted in 2005 and 2011 also showed the prevalence of diarrhea under five in the two weeks period to be $24 \%$ and $13 \%$, respectively (CSA, 2012).

Giardia intestinalis, Cryptosporidium spp., and Entamoeba histolytica/dispar are widely distributed diarrhea causing protozoans in Ethiopia (Tsehay Assefa et al., 1996). Reports from different parts of Ethiopia show different prevalence rates of these parasites. For instance, among under five children who visited University of Gondar Hospital, 12\% them were infected by G. intestinalis (Yetemwork Aleka et al., 2015). Among diarrheic under five children who visited two health facilities in Hawassa town, $11.4 \%$ and $7 \%$ them were

\footnotetext{
*Corresponding author:endtg2002@yahoo.com

(C) This is an Open Access article distributed under the terms of the Creative Commons Attribution License (http://creativecommons.org/licenses/CC BY4.0).
} 
infected by E. histolytica/dispar and G. intestinalis, respectively (Getamesay Mulatu et al., 2015).

Exposure to diarrhea causing pathogens is conditioned by factors like age of the child, quality and quantity of water, availability of toilet facilities, housing conditions, level of education, household economic status, place of residence, feeding practices, and the general sanitary conditions (personal or domestic hygiene) around the house (Stephen, 2005). It is, therefore, very important to determine the interaction of these factors in relation to child's survival. However, information on the prevalence of these protozoans and the associated risk factors in children living in Bahir Dar town is limited. Hence, the present study was undertaken to determine the prevalence of diarrhea causing intestinal protozoan infections and associated risk factors in under five children presenting with diarrheal disease.

\section{MATERIALS AND METHODS}

\section{Study area, design and period}

Pediatric clinics based study on diarrhea causing protozoans was conducted from November 2011 to February 2012 in Bahir Dar town, Amhara National Regional State, Ethiopia. Bahir Dar town is found at the geographic coordinates of $11^{\circ} 29^{\prime}-11^{\circ} 41^{\prime}$ 'North latitudes and $37^{\circ} 16^{\prime}$ $37 \circ 27^{\prime}$ East longitudes, on the southern side of Lake Tana. It is located at an elevation of 1795 meters above sea level and covers an area of 16,000 hectares. The mean annual precipitation depth recorded in 37 years period from 1962 to 1999 was about $1437 \mathrm{~mm}$. The area experiences an average annual rain fall ranging from 1200 $1600 \mathrm{~mm}$ and a mean annual temperature of $26^{\circ} \mathrm{C}$ (Abel Markos, 2012). Data was collected from Arsema and Universal Pediatric Clinics, which had a capacity to treat 257 and 193 children per month, respectively.

\section{Sample size determination and sampling technique}

The sample size (n) was calculated using statistical formula of sample size calculation, $n=Z^{2} P(1-P) / d^{2}$ (Danile, 1999).

Where, $\mathrm{n}=$ the minimum sample size required, $\mathrm{Z}=$ standard score corresponds to 1.96 at $95 \%$ confidence interval, $d=$ is margin of sampling error tolerated ( $5 \%$ marginal error was used), $p=$ prevalence of intestinal protozoa. Since the overall prevalence of intestinal protozoa in the specific study subjects in the study area was unknown, a prevalence of $50 \%$ was considered for the calculation of sample size and a sample size of 384 was obtained. To minimize errors from the likelihood of non-compliance, $10 \%$ of the sample size was added and a final sample size of 422 was considered in the study.

All diarrheic children aged below five years who visited the only two private pediatric clinics (Arsema and Universal Pediatric Clinics) in Bahir Dar town and who were not on anti-protozoal drugs within fifteen days before the commencement of stool specimen collection were selected for study. The diarrheic children were distinguished from non-diarrheic children based on the passage of unusually consistent loose or watery stools, usually at least three times in a 24 hour period (WHO, 2005).

\section{Data collection and laboratory analysis}

A questionnaire was developed based on known risk factors and to fill the questionnaire caretakers/ mothers were interviewed by medical doctor and nurse during clinical examination. The questionnaires included socio-demographic, environmental and behavioral factors that expose the children to protozoal infection. 
After proper instruction of caretakers about stool collection, about $2 \mathrm{~g}$ of fresh stool was collected from each child. Every specimen was checked for its label, quantity, and procedure of collection. The collected stool specimens were immediately transported to Bahir Dar University Biomedical Sciences Research Laboratory. Stool examinations were performed using direct saline and formol-ether concentration technique by a trained laboratory technician (WHO, 2000). For the detection of Cryptosporidium spp., Modified Ziehl-Neelsen method was used (WHO, 2003). To ensure validity of the slide test, all positive slides and random sample of some of the negative slides were re-examined by another experienced laboratory technician who was blind to the diagnosis of the first slide-reader.

\section{Data management and analysis}

Data were entered and analyzed using SPSS version 16 software. Initially the association between exposure and the presence of infection was assessed using Chi-square test. Crude Odds Ratio (COR) was then determined using univariate logis-

Table 1. Socio-demographic characteristics of households of the study subjects and their caretakers in Bahir Dar town, 2011.

\begin{tabular}{|c|c|c|c|c|c|c|}
\hline \multirow{2}{*}{\multicolumn{2}{|c|}{ Characteristic }} & \multirow{3}{*}{$\begin{array}{c}\text { Frequency } \\
239\end{array}$} & \multirow{3}{*}{$\begin{array}{c}\text { Percentage } \\
56.6\end{array}$} & \multicolumn{2}{|c|}{ Protozoal infection } & \multirow[t]{3}{*}{ P-value } \\
\hline & & & & Positive (\%) & Negative (\%) & \\
\hline \multirow[t]{2}{*}{ Sex } & Male & & & $57(23.8)$ & $182(76.2)$ & \\
\hline & Female & 183 & 43.4 & $29(15.8)$ & $154(84.2)$ & \multirow{2}{*}{0.046} \\
\hline \multirow[t]{3}{*}{ Caretaker } & Father & 28 & 6.6 & $6(21.4)$ & $22(78.6)$ & \\
\hline & Mother & 372 & 88.2 & $71(19.1)$ & $301(80.9)$ & \multirow[b]{2}{*}{0.047} \\
\hline & Guardian & 22 & 5.2 & $9(40.9)$ & $13(59.1)$ & \\
\hline \multirow[t]{2}{*}{ Residence } & Urban & 403 & 95.5 & $76(18.9)$ & $327(81.1)$ & \multirow{2}{*}{$<0.001$} \\
\hline & Rural & 19 & 4.5 & $10(52.6)$ & $9(47.4)$ & \\
\hline \multirow{4}{*}{$\begin{array}{l}\text { Educational } \\
\text { status }\end{array}$} & 1-6 grade & 47 & 11.1 & $11(23.4)$ & $36(76.6)$ & \multirow[b]{4}{*}{$<0.001$} \\
\hline & $7-12$ grade & 169 & 40.1 & $28(16.6)$ & $141(83.4)$ & \\
\hline & 12 completed $^{+}$ & 138 & 32.7 & $19(13.8)$ & $119(86.2)$ & \\
\hline & $\begin{array}{l}\text { No formal } \\
\text { education }\end{array}$ & 68 & 16.1 & $28(41.2)$ & $40(58.8)$ & \\
\hline \multirow[t]{6}{*}{ Occupation } & Government & 89 & 21.1 & $16(18)$ & $73(82)$ & \\
\hline & Non-government & 14 & 3.3 & $2(14.3)$ & $12(85.7)$ & \\
\hline & Private & 16 & 3.8 & $3(18.8)$ & $13(81.2)$ & \\
\hline & Self-employee & 302 & 71.6 & $65(21.5)$ & $237(78.5)$ & \\
\hline & Others & & & & & \\
\hline & $\begin{array}{l}\text { (e.g. retired } \\
\text { individuals, } \\
\text { freelancer) }\end{array}$ & 1 & 0.2 & $0(0.0)$ & $1(100)$ & 0.008 \\
\hline
\end{tabular}


tic regression method to measure the strength of association. To determine independent effect of each of the risk factors, Adjusted Odds Ratio (AOR) was determined using multivariate logistic regression. $\mathrm{P}$-values less than 0.05 were considered to be statistically significant.

\section{Ethical considerations}

The study was reviewed and approved by the Ethical Review Board of Bahir Dar University. Official letter was submitted to Arsema and Universal Pediatric Clinics. Both informed verbal and written consent were sought from the mothers/ caretakers of each diarrheic child. The purpose of the study was explained and sufficient time was given for the interviewees to decide whether to participate in the study or not. The positive cases got treatment from the clinics.

\section{RESULTS}

\section{Socio-demographic characteristics}

A total of 422 diarrheic children were included for examination. Of these, $239(56.6 \%)$ were males and $183(43.4 \%)$ were females. The mean age of the study participant was 16.7 months and most of them $(80.9 \%)$ were under the care of their mothers (Table 1).

\section{Prevalence of intestinal protozoal infection}

The overall prevalence of intestinal protozoal infection was $20.4 \%(86 / 422)$. The prevalence of $E$. histolytica/dispar was $15.2 \%$, G. intestinalis $0.9 \%$, Cryptosporidium spp. 3.8\%, both Cryptosporidium spp. and E. histolytica/dispar $0.5 \%$ (Table 2). In terms of sex, the overall prevalence of protozoal infection was $23.8 \%$ in males and $15.8 \%$ in females (Table 1). The prevalence of infection was $11.5 \%$ for the age category of $0-5$ months, $13.6 \%$ for $6-11$ months, $32.6 \%$ for $12-23$ months, $20.0 \%$ for $24-35$ months, $14.3 \%$ for $36-47$ months, and $10.5 \%$ for 48-59 months of age. Children aged 48-59 months were the least affected group with a prevalence of $10.5 \%$. Although single parasite infection had the highest prevalence, there was also double infection due to Entamoeba histolytica/dispar and Cryptosporidium spp. (Table 2).

Table 2. Prevalence of intestinal protozoal parasites in children in different age groups in Bahir Dar town, 2011.

\begin{tabular}{lllllll}
\hline $\begin{array}{l}\text { Age of } \\
\text { child } \\
\text { (months) }\end{array}$ & $\begin{array}{l}\text { № of } \\
\text { children } \\
\text { examined }\end{array}$ & \multicolumn{5}{c}{ Children positive for, N(\%) } \\
& & Cryptosporidium & Entamoeba & Giardia & Cryptosporidium & infected \\
\hline $0-5$ & 61 & $5(8.2)$ & $2(3.28)$ & $0(0.0)$ & $0(0.0)$ & $7(11.48)$ \\
$6-11$ & 118 & $7(5.9)$ & $8(6.8)$ & $0(0.0)$ & $1(0.8)$ & $16(13.6)$ \\
$12-23$ & 141 & $2(1.4)$ & $42(29.8)$ & $2(1.4)$ & $0(0.0)$ & $46(32.6)$ \\
$24-35$ & 55 & $1(1.8)$ & $9(16.4)$ & $1(1.8)$ & $0(0.0)$ & $11(20.0)$ \\
$36-47$ & 28 & $1(3.6)$ & $1(3.6)$ & $1(3.6)$ & $1(3.6)$ & $4(14.3)$ \\
$48-59$ & 19 & $0(0.0)$ & $2(10.5)$ & $0(0.0)$ & $0(0.0)$ & $2(10.5)$ \\
\hline Total & 422 & $16(3.8)$ & $64(15.2)$ & $4(0.9)$ & $2(0.5)$ & $86(20.4)$ \\
\hline
\end{tabular}


Table 3. Environmental condition and sanitation and hygiene practices of the study subjects and their caretakers in Bahir Dar town, 2011.

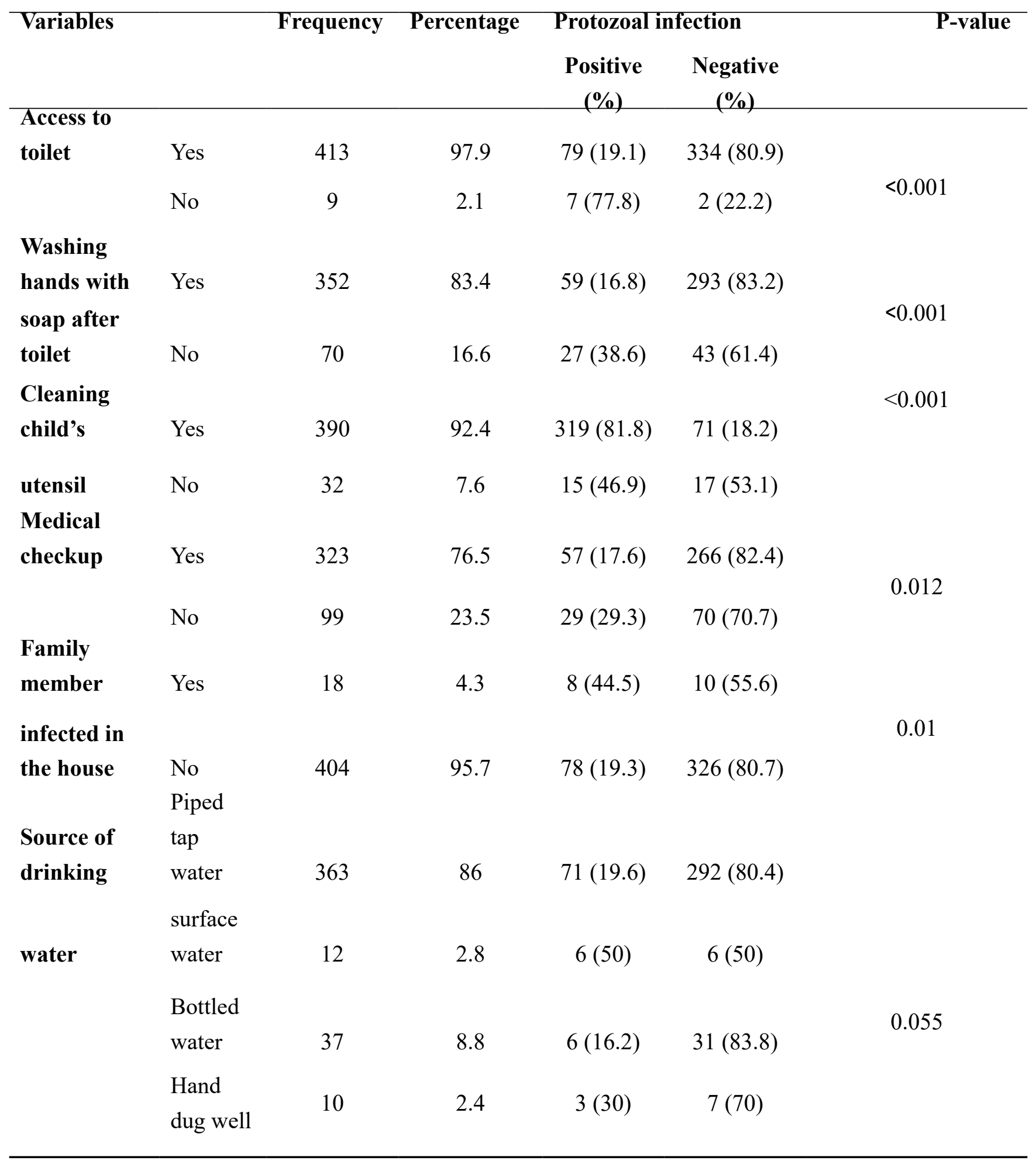


Sanitation and hygiene characteristics

Most $(97.9 \%$; 413/422) of households had toilet whereas the rest $(2.1 \% ; 9 / 422)$ had no toilet. About $86 \%$ (363) used tap water, 8.8\% (37) bottled water, $2.8 \%$ (12) untreated surface water, $2.4 \%$ (10) hand dug well (Table 3 ).

\section{Behavioral and breast feeding characteristic of the caretakers}

Three-hundred ninety eight $(94.3 \%)$ mothers breastfed their children up to six months of age and the $24(5.7 \%)$ stopped breastfeeding their child before the age of six months. From those mothers who started giving additional food to their children, 120 (28.4\%) started giving food before the children reached the age of six months (Table 4).
Potential risk factors of intestinal protozoal infection

Prevalence of infection varied across socio-demographic, environmental, and behavioral characteristics of caretakers/mothers (Tables 5-7). The likelihood of having diarrhea because of intestinal protozoal infection in children whose caretakers had no formal education was twelve times higher than in those whose parents were literate (AOR: 12.0; 95\% CI: 2.97-48.51: p-value $<0.001)$. The odds of being diarrheic were eight times higher in children aged of 12-23 months than in those children aged 48-59 months (AOR: 8.69; 95\% CI: 1.50-27.50; p-value 0.004). The prevalence of intestinal protozoal infection was not significantly as-

Table 4. Behavioral and breastfeeding practices of the parent/caretaker in Bahir Dar town, 2011.

\begin{tabular}{|c|c|c|c|c|c|}
\hline \multirow{2}{*}{ Characteristic } & \multirow{2}{*}{ Frequency } & \multirow{2}{*}{ Percentage } & \multicolumn{2}{|c|}{ Protozoal infection } & \multirow[t]{2}{*}{ P-value } \\
\hline & & & Positive (\%) & Negative (\%) & \\
\hline \multicolumn{5}{|c|}{ Breastfeeding children up to six months } & \multirow{3}{*}{$<0.001$} \\
\hline Yes & 398 & 94.3 & $70(17.6)$ & $328(82.4)$ & \\
\hline No & 24 & 5.7 & $16(66.7)$ & $8(33.3)$ & \\
\hline \multicolumn{5}{|c|}{ Exclusive breastfeeding the child up to the first six months } & \\
\hline Yes & 271 & 64.2 & $31(11.4)$ & $240(88.6)$ & \multirow{2}{*}{$<0.001$} \\
\hline No & 151 & 35.8 & $55(36.4)$ & $96(63.6)$ & \\
\hline \multicolumn{5}{|c|}{ Vitamin A supplementation } & \multirow{3}{*}{0.461} \\
\hline Yes & 372 & 88.2 & $78(21)$ & $294(79)$ & \\
\hline No & 50 & 11.8 & $8(16)$ & $42(84)$ & \\
\hline \multicolumn{5}{|l|}{ Bottle feeding } & \multirow{3}{*}{0.043} \\
\hline Yes & 249 & 59 & $59(23.7)$ & $190(76.3)$ & \\
\hline No & 173 & 41 & $27(15.6)$ & $146(84.4)$ & \\
\hline \multicolumn{5}{|c|}{ Start of complementary feeding } & \multirow{3}{*}{$<0.001$} \\
\hline Before six months & 120 & 28.4 & $49(40.8)$ & $71(59.2)$ & \\
\hline Above six months & 302 & 71.6 & $37(12.3)$ & $265(87.7)$ & \\
\hline
\end{tabular}


Table 5. Logistic regression analysis of socio-demographic variables in relation to prevalence of intestinal protozoal parasites in Bahir Dar town, 2011.

\begin{tabular}{|c|c|c|c|c|}
\hline Characteristics & $\begin{array}{c}\text { Crude OR } \\
(95 \% \mathrm{CI})\end{array}$ & P-value & $\begin{array}{l}\text { Adjusted Odds } \\
\text { ratio }(95 \% \mathrm{CI})\end{array}$ & P-value \\
\hline \multicolumn{5}{|l|}{ Age of child ( months) } \\
\hline $05 \mathrm{~V} 41850 * *$ & 1.10 & & 2.97 & \\
\hline 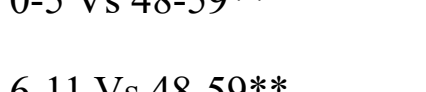 & $(0.18,8.52)$ & & $(0.27,31.72)$ & 0.367 \\
\hline $0-11$ V $28-20 x^{2}$ & $(0.26,9.22)$ & & $(0.23,19.05)$ & 0.502 \\
\hline $12-23$ Vs $48-59 * *$ & $(0.86,26.97)$ & & $(1.50,27.09)^{*}$ & $0.004 *$ \\
\hline $24-35$ Vs 48-59** & $\begin{array}{c}(0.38,15.52) \\
0.19\end{array}$ & 0.001 & $\begin{array}{c}(0.70,71.87) \\
4.66\end{array}$ & 0.097 \\
\hline $\begin{array}{l}36-47 \text { Vs } 49-60 * * \\
\text { Educational status of }\end{array}$ & $(0.19,12.76)$ & & $(0.31,70.13)$ & 0.265 \\
\hline parents & 4.38 & & 12.0 & \\
\hline Illiterate Vs tertiary** & $(2.10,9.21)^{*}$ & & $(2.97,48.51)^{*}$ & $<0.001^{*}$ \\
\hline Primary Vs tertiary** & $\begin{array}{c}1.19 \\
(0.77,4.72)\end{array}$ & & $\begin{array}{c}2.85 \\
(0.57,14.13)\end{array}$ & 0.199 \\
\hline $\begin{array}{l}\text { Secondary Vs } \\
\text { tertiary** }\end{array}$ & $\begin{array}{c}1.24 \\
(0.63,2.45)\end{array}$ & 0.001 & $\begin{array}{c}1.93 \\
(0.68,5.50)\end{array}$ & 0.213 \\
\hline
\end{tabular}

** Reference group * Significant at $\mathrm{p}<0.05$.

sociated with marital status, care taker relation, and parental occupation $(\mathrm{p}>0.05)$ (Table 5).

From the environmental factors analyzed, factors like washing hands after toilet, presence/absence of individuals in the family infected by protozoa, having regular medical checkup, and frequency of cleaning the child's feeding materials remained significant in the final step of multivariate analysis (Table 6). Washing hands with soap after visiting toilet showed significant association with protozoal infection where the risk of protozoal infection was three times higher in children whose caretakers did not wash their hands after visiting toilet than in those caretakers who washed their hands after toi- let (AOR: 3.20; 95\% CI:1.04-9.81; p-value 0.042). Frequency of washing the child's feeding utensils was also associated with infant diarrhea morbidity, where a higher proportion of children whose feeding materials were washed less frequently experienced diarrhea compared to children whose feeding utensils were washed frequently (AOR: 6.57; 95\% CI: 3.63-118.00; p-value 0.005) (Table 6).

Regular medical checkup of the child's caretaker was also associated with the risk of infection by protozoa. Children whose caretakers undergo regular medical checkup were less likely to be infected compared to those children whose caretakers who did not undergo medical checkup (AOR: 48.67; 
95\% CI: 8.87-266.9; p-value $<0.001)$. The presence of family members infected by protozoa was also significantly associated with diarrheal morbidity (AOR: 8.64; 95\% CI: 1.42-52.59; p-value 0.019).

Availability of toilet, and type of water source (untreated surface water versus bottled water) showed significant associations in the univariate analysis, but their significance disappeared in the final step of the multivariate analysis ( $p>0.05)$ (Table 6).

From the behavioral factors entered in the first step of multivariate analysis, using complementary food, duration of breast feeding, and bottle feeding practice remained significant in the final step of the analysis (Table 7). Duration of breast feeding was important risk factor for diarrhea morbidity. The risk of infection by protozoa was significantly higher for those children who were breastfed less than six months of duration compared with infants who were breastfed up to six months (AOR: 6.57; 95\% CI: 1.58-27.31; p-value 0.01).

Exclusive breast feeding is very important for infants especially in the first six months of age. Infants who were exclusively breastfed in the first six months of age were less likely to be infected by protozoa compared to infants who were not exclusively breastfed (AOR: 6.99; 95\% CI: 1.79-27.31;

Table 6. Logistic regression analysis of sanitation and hygiene conditions in relation to prevalence of intestinal protozoal parasites in Bahir Dar town, 2011.

\begin{tabular}{|c|c|c|c|}
\hline Characteristics & $\begin{array}{c}\text { Crude OR } \\
95 \% \text { CI }\end{array}$ & P-value & $\begin{array}{c}\text { Adjusted Odds ratio } \\
95 \% \text { CI }\end{array}$ \\
\hline
\end{tabular}

\section{Washing hands with soap after visiting toilet}
Yes** vs No
3.12
3.20
$(1.72,5.64)^{*}$
$0.001^{*}$
$(1.04,9.81)^{*}$
$0.042 *$

Cleaning the child's utensil frequently
Yes** Vs No
3.96
$(1.78,8.82)^{*}$
$0.001 *$
6.57
$(3.63,118)^{*}$
$0.005^{*}$

Family member infected in the house
Yes Vs No**
3.34
$(1.16,9.55)^{*}$
$0.010^{*}$
8.64
$(1.42,52.59)^{*}$
$0.019^{*}$

Medical checkup

Yes** Vs No

1.93

48.67*

$(1.11,3.35)^{*} \quad 0.010^{*} \quad(8.87,266.90) \quad 0.001 *$

** Reference group * Significant at $\mathrm{p}<0.05$. 
Table 7. Logistic regression analysis of behavioral variables in relation to prevalence of intestinal protozoal parasites in Bahir Dar town, 2011.

$\begin{array}{llll}\text { Characteristics } & \text { Crude OR (95\%CI) } & \text { P-value } & \begin{array}{l}\text { Adjusted Odds } \\ \text { ratio (95\% CI) }\end{array}\end{array}$

\begin{tabular}{|c|c|c|c|c|}
\hline \multicolumn{5}{|c|}{ Breastfeeding the child up to six months } \\
\hline \multirow{2}{*}{ Yes** vs No } & 9.37 & & 6.57 & \\
\hline & $(3.60,25.0)^{*}$ & $0.001 *$ & $(1.58,27.31)^{*}$ & $0.010^{*}$ \\
\hline \multicolumn{5}{|c|}{ Exclusive breastfeeding up to the first six months } \\
\hline \multirow{2}{*}{ Yes** vs No } & 4.44 & & 6.99 & \\
\hline & $(2.62,7.54)$ & $0.001 *$ & $(1.79,27.31)$ & $0.005^{*}$ \\
\hline \multicolumn{5}{|l|}{ Bottle feeding } \\
\hline \multirow{2}{*}{ Yes Vs No** } & 1.76 & & 5.22 & \\
\hline & $(1.03,2.87)^{*}$ & $0.040^{*}$ & $(1.15,23.63)^{*}$ & $0.032 *$ \\
\hline \multicolumn{5}{|l|}{ Complementary feeding } \\
\hline Before six vs above six & 4.94 & & 15.88 & \\
\hline month** & $(2.91,8.42)^{*}$ & $0.001 *$ & $(3.03,83.18)^{*}$ & $0.001 *$ \\
\hline
\end{tabular}

** Reference group * Significant at $\mathrm{p}<0.05$.

p-value 0.005). Method of infant feeding was significantly associated with diarrheal morbidity in the multivariate analysis, where the odds of having diarrhea in children who were fed using bottle were five times higher in children who were not fed using bottle (AOR: 5.22; 95\% CI: 1.15-23.63; p-value 0.032 ). Even though vitamin-A supplementation showed significant association in the univariate analysis, the association disappeared in the multivariate analysis $(\mathrm{p}>0.05)$.

\section{DISCUSSION}

The overall prevalence of protozoa infection in the present study was $20.4 \%$. This figure is lower than the prevalence reported in children under five in Ghana (38\%) (Osumanu, 2010). The prevalence in the study area was higher when compared with the prevalence reported from Vietnam (11.3\%) (Takanashi et al., 2009), Kenya (16.7\%) (Onyango and Angienda, 2010), and Thailand (8.2\%) (Wilunda and Panza, 2009). A relatively higher prevalence in Bahir Dar town might be due to the poor hygienic and sanitary condition of children and their caretakers.

The prevalence of Entamoeba histolytica/dispar $(15.2 \%)$ in the present study was consistent with the finding conducted in preschool children in Bangladesh (15.6\%) (Ali et al., 2003), but it is quiet lower when compared with the prevalence of Entamoeba in Nigeria (65.7\%) (Ogunlesi et al., 2006). This figure is higher than the prevalence reported in children under five in Jeddah (2.2\%), Saudi Arabia (El-Sheikh and El-Assouli, 2001). The high prevalence of the parasite in Bahir Dar town can be attributed to its direct transmission through contaminated water and food as well as the low standards of hygiene, sanitation, and low level of education of the caretakers.

The prevalence of Cryptosporidium spp. in the present study was $3.8 \%$, which is comparable with the prevalence of Cryptosporidium spp. infection in children in North America (0.6-4.3\%) and Austra- 
lia (3-10.2\%) (Frost et al., 2000). But, it is much lower when compared with the prevalence reported from Shiraz, Iran (21.4\%) (Nahrevanian and Assmar, 2008) and Nigeria (19.9\%) (Dozie et al., 2011). The low prevalence of Cryptosporidium spp. may be due to the intermittent nature of excretion of oocysts by the parasite (Navin and Juranek, 1984). It is possible that the infection rate observed in the present study would have been even higher, if more than a single stool specimen was collected from each child.

In the case of $G$. intestinalis, the prevalence in the present study $(0.9 \%)$ was comparable with the prevalence conducted in children in Italy $(0.8 \%)$ (Guidetti et al., 2010) and United Kingdom (1.3\%) (Davies et al., 2009). But, this figure was lower than the prevalence of giardiasis in Dire Dawa, Ethiopia (38\%) (Dawit Ayalew, 2006) and that of Bangladish (3.8\%) (Suman et al., 2011). The low prevalence in the present study may be due to the lack of appropriate diagnostic method to detect low levels of parasite burden or it may be due to the variation of occurrence of cysts excretion of the parasite (Garcia, 2007).

From the socio demographic factors, educational status of mothers/ caretakers and age of children remained significant in the multivariate analysis, indicating the two factors as independent risk factors for the occurrence of diarrhea in children under five years in Bahir Dar town. Children whose mothers/ caretakers had some form of education were less affected by intestinal protozoal infection. This finding is consistent with reports from Mexico (Camacho, 2006) and Ghana (Boadi and Kuitunen, 2003). This could be because educated mothers practice good hygiene, better child feeding and weaning practices and the interpretation of symptoms and timely action to childhood illness, all of which increase a child's resistance against infectious diseases (Frost et al., 2005).
Child's age was found to be a significant predictor of diarrheal morbidity due to protozoa in children in the age category of 12-23 months. This is might be because of the combined effect of the low level of maternal acquired immunity, the introduction of food or liquid contaminated with pathogens, and direct contact with human and animal excreta when the child starts to crawl (Usfar et al., 2010). On the contrary, children in the age category of 48-59 months and above are less vulnerable to diarrhea because of the protective effects of a relatively prolonged breastfeeding and the less exposure to contaminated agents (Piechulek et al., 2003).

The likelihood of transmitting diarrhea in those caretakers who were reluctant in having regular medical checkup for their health even when they look healthy was very high. This is because usually caregivers of the children who look asymptomatic may harbor numerous parasites whether they have diarrhea or not and as a result, the chance of transmitting the infection is very high (Young and Briscoe, 1987). For example, in the case of E. histolytica/dispa, in up to $90 \%$ of the infections, the symptoms are absent or very mild and the infected individuals serve as unidentified carriers and may become responsible for transmission (Gatti et al., 2002).

Children whose caretakers who did not wash their hands with soap after visiting toilet were more infected by intestinal protozoans compared to children whose caretakers washed their hands with soap after visiting toilet. The result is consistent with a study conducted in Turkish school children (Ostan et al., 2007). It is clear that washing hands with soap reduces the infectious organisms present on the hands thereby reducing diarrheal episode by 31\% (Ejemot et al., 2008). Other similar studies have also shown that washing hands with soap regularly has reduced the risk of intestinal diseases in children (UNICEF/WHO, 2009). 
Whenever there is a family member who was infected by protozoa in the same house, it was shown that it is a significant predictor of diarrheal morbidity in children. In other study it has been shown that an eight fold increase in the odds of catching diarrhea due to protozoa in children. This shows that a higher probability of exposing children to infectious agents from food handlers of the family and childcare providers (Medeiros et al., 2004). Moreover, the health of the child may be compromised if the food items/bottles are easily contaminated by flies.

Higher proportion of children whose feeding materials were washed less frequently experienced diarrhea than infants whose feeding utensils were washed frequently. This is because less frequently washed infants' feeding materials are more susceptible to contamination by flies, cockroaches, and hands of the caretakers. So, frequent washing of the child's feeding material reduces the infectious organism present on it and this observation agrees with the findings that were reported by Holt et al. (2007).

Breastfeeding protects children from infection particularly in the first three months of life (Butte et $a l ., 2002)$. This is because breast milk contains oligosaccharides, immunoglobulin-A (IgA), and lactoferrin that have been shown to protect the child from gastro- enteritis (Hanson and Korotkova, 2002). In addition, the use of breast milk also offers fewer opportunities for the infant not to become infected from other foods and water (PATH, 2008). The present study showed that children who were not breastfed in the first six months were at higher risk of developing diarrhea.

Exclusive breast feeding reduces exposure of the child to contaminated foods, drinking water, and feeding utensils. According to WHO (2001), the optimal duration of exclusive breastfeeding is very important for the first six months. In present study it was revealed that those infants who were not exclusively breastfed in the first six months of age were more infected by protozoans compared to infants who were exclusively breastfed. The present finding is consistent with findings reported from India (Dabasmita and Bratati, 2005) and Belarus (Kramer et al., 2003).

The introduction of other liquids or foods marks the beginning of a child's exposure to possibly contaminated foods and liquids (Dewey et al., 2001). Ideally, complementary foods should be introduced at age of six months and breastfeeding should continue for up to two years or even longer to increase birth intervals (WHO, 2003). The result of multivariate analysis showed that the risk of developing diarrhea due to protozoa was fifteen times higher in children who started complementary feeding before the age of six months than those children who started after six months. This could be because infant who were weaned too early will lack antibodies and nutrients supplied by breast milk, which could expose them to different parasitic infections (Dewey et al., 2001).

It has been documented that there is a high chance of contamination and greater risk of diarrhea associated with bottle feeding (Holt et al., 2007). In this study, bottle feeding was significantly associated with intestinal protozoal infection. This is because bottles are highly susceptible and exposed for contamination by flies and fecally contaminated hands (Holt et al., 2007).

Due to cross-sectional nature of the study and budget constraint, difference in the prevalence of infection in dry and wet seasons was not assessed. The study would also underestimate the actual prevalence of Cryptosporidium spp., as the less Modified Ziehl-Neelsen method was used for the detection of the parasite. Moreover, since light microscopy fails to identify between E. histolytica 
and E. dispar, in this study the two species were considered as diarrhea causing parasites but only the former is pathogenic and the latter is the predominant species.

\section{CONCLUSION}

In the present study, a relatively high prevalence of intestinal protozoal infection was recorded in children under five years of age. Such a high prevalence was found to be associated with education level of caretakers, personal hygiene, health status, lack of knowledge in using bottles appropriately, lack of knowledge when to start supplementary feeding, and problem of cleaning child's feeding materials. Providing proper education on sanitation, hygienic practice and potential risk factors to the community would help the reduction of higher prevalence of diarrhea. A detailed further study is required to identify other infectious agents and other potential risk factors to fully explain the observed diarrhea under five children in Bahir Dar town. Moreover, the seasonal variation of the prevalence of diarrhea due to protozoans and other diarrhea causing organisms should be studied.

\section{ACKNOWLEDGEMENTS}

We thank all the children, their parents /guardians, and data collectors who participated in the study. We would also thank Bahir Dar University for providing us fund to carry out this research.

\section{REFERENCES}

Abel Markos. (2012). Web GIS for tourism development of Bahir Dar town and its surroundings. M.Sc. thesis, Addis Ababa University, Ethiopia.

Ali, I.K., Hossain, M.B., Roy, S., Ayeh-Kumi,
P.F., Petri, W. A., Haque, R and Clark, C.G. (2003). Entamoeba moshkovskii infections in children, Bangladesh. Journal of Emerging Infectious Diseases 9: 580-584.

Black, R.E., Cousens, S., Johnson, H.L., Lawn, J.E and Rudan, I. (2010). Global, regional, and national causes of child mortality in 2008: a systematic analysis. Lancet 375: 1969-1987.

Boadi, K.O and Kuitunen, M. (2005). Childhood diarrheal morbidity in the Accra metropolitan area, Ghana: socioeconomic, environmental and behavioral risk determinants. Journal of Health and Population in Developing Countries. Article ID 17646, pp33-46.

Butte, N.F., Lopez-Alarcon, M.G and Garza, C. (2002). Nutrient adequacy of exclusive breast-feeding for the term infant during the first six months of life. In: Expert Consultation on the Optimal Duration of Exclusive Breastfeeding (WHO, 2001) Geneva.

Camacho, S.P. (2006). Role of the employment status and education of mothers in the prevalence of intestinal parasitic infections in Mexican rural school children. BMC Public Health 6: 225-232.

CSA [Ethiopia] and ICF International; 2012. Ethiopia Demographic and Health Survey 2011. Addis Ababa, Ethiopia and Calverton, Maryland, USA: Central Statistical Agency and ICF International.

Dabasmita, B and Bratati, B. (2005). Influence of child care practice on prevalence of diarrheal disease. Indian Pediatrics 42: 497-98.

Danile, W.W. (1999). Biostatistics a foundation for analysis in the health science. $7^{\text {th }}$ edition. John Willey and Sons Inc, New York. 
Davies, A.P., Campbell, B., Evans, M.R., Bone, A., Roche, A and Chalmers, R.M. (2009). Asymptomatic carriage of protozoan parasites in children in day care centers in the United Kingdom. Journal of Pediatrics Infectious Disease 28: 838-840.

Dawit Ayalew. (2006). Assessment of the association of Cryptosporidium parvum, Giardia lamblia and Entamoeba histolytica/dispar infection prevalence with drinking water source among children in Legedini, Adada and Legfbira, Dire-Dawa, Eastern Ethiopia. M.Sc. Thesis. Addis Ababa University, Ethiopia.

Dewey, K.G., Cohen, R.J., Brown, K.H and Rivera, L.L. (2001). Effects of exclusive breastfeeding for 4 versus 6 months on maternal nutritional status and infant motor development: results of two randomized trials in Honduras. Journal of Nutrition 131: 262-267.

Dozie, I., Nkem, B.I and Chukwuocha, U. (2011). Cryptosporidiosis in Imo State, Nigeria Rural. Journal of Tropical Public Health 10: 106110.

Ejemot, R.I., Ehiri, J.E., Meremikwu, M.M and Critchley, J.A. (2008). Hand washing for preventing diarrhoea. Cochrane database of systematic reviews.

Elias, C.J. (2008). Diarrhea Disease: Emergency and Humanitarian Action (EHA) WHO. Geneva.

El-Sheikh, S.M and El-Assouli, S.M. (2001). Prevalence of viral, bacterial and parasitic enteropathogens among young children with acute diarrhea in Jeddah, Saudi Arabia. Journal of Health, Population and Nutrition 19: 25-30.
Frost, F.J., Muller, T and Craun, G. (2000). Serological analysis of a cryptosporidiosis epidemic. International Journal of Epidemiology 29: 376-379.

Frost, M.B., Forste, R and Haas, D.W. (2005). Maternal education and child nutritional status in Bolivia: finding the links. Journal of Social Science and Medicine 60: 395-407.

Garcia, L.S. (2007). Medical Parasitology: Case Histories. In: Diagnostic Medical Parasitology, pp.988-1026 (Garcia, LS (ed). $5^{\text {th }}$ edition. ASM Press, Washington, DC.

Gatti, S., Swierczynski, O., Robinson, F., Anselmi, $\mathrm{M}$ and Correles, J. (2002). Amoebic infections due to the Entamoeba histolytica/dispar complex: a study of the incidence in a remote rural area of Ecuador. American Journal of Tropical Medicine and Hygiene 67: 123-127.

Getamesay Mulatu, Ahmed Zeynudin, Endalew Zemene, Serkadis Debalke and Getenet Beyene. (2015). Intestinal parasitic infections among children under five years of age presenting with diarrhoeal diseases to two public health facilities in Hawassa, South Ethiopia. Infectious Diseases of Poverty 4:49.

Guidetti, C., Ricci, L and Vecchi, L. (2010). Prevalenza delle parassitosi intestinali a Reggio Emiliae Provincia nel corso del 2009 [abstract]. Le Infezioni in Medicina 3: 154-161.

Hanson, L.A and Korotkova, M. (2002). The role of breastfeeding in prevention of neonatal infection. Seminars in Neonatology 7: 275-281.

Holt, P.S., Geden, C.J., Moore, R.W and Gast, R.K. (2007). Isolation of Salmonella enterica serovar enteritidis from houseflies (Musca domestica) found in rooms containing Salmonel- 
la serovar enteritidis-challenged hens. Applied Environmental Microbiology 73: 6030-6035.

Kramer, M.S., Guo, T., Platt, R.W., Sevkovskaya ,Z., Dzikovich, I., Collet, J.P., Shapiro, S., Chalmers, B., Hodnett, E., Vanilovich, I., Mezen, I., Ducruet, T., Shishko, G and Bogdanovich, N. (2003). Infant growth and health outcomes associated with 3 compared with 6 months of exclusive breastfeeding. American Journal of Clinical Nutrition 78: 291- 295.

Medeiros, L.C., Hillers, V.N., Chen, G., Bergmann, V., Kendall, $\mathrm{P}$ and Schroeder, M. (2004). Design and development of food safety knowledge and attitude scales for consumer food safety education. Journal of American Dietetic Association 104: 1671-1677.

Nahrevanian, H and Assmar, M. (2008). Cryptosporidiosis in immunocompromised patients in the Islamic Republic of Iran. Journal of Microbiology, Immunology and Infection 41: 74-77.

Navin, T.R and Juranek, D.D. (1984). Cryptosporiodosis. Clinical, epidemiologic, and parasitologic review. Reviews of Infectious Disease 6: $313-327$.

Ogunlesi, T., Okeniyi, J., Oseni, S., Oyelami, O., Njokanma, F and Dedeke, O. (2006). Parasitic etiology of childhood diarrhea. Indian Journal of Pediatrics 73: 1081-1084.

Onyango, D.M and Angienda, P.O. (2010). Epidemiology of waterborne diarrheal disease among children aged 6-36 months old in Busia -Western Kenya. World Academy of Science, Engineering and Technology 37: 1013-1020.

Ostan, I., Kilimciolu, A.A., Girginkardeler, N.,Ozyurt, B.C and Limoncu, M.E. (2007).
Health inequities: lower socioeconomic conditions and higher incidences of intestinal parasites. BMC Public Health 7: 342-350.

Osumanu, I.K. (2010). Household environmental and behavioral determinants of childhood diarrhea morbidity in the Tamale Metropolitan Area (TMA), Ghana. Danish Journal of Geography 107: 59-68.

PATH (Program for Appropriate Technology in Breast feeding and diarrhea; 2013.

Piechulek, H., Al-Sabbir, A and Mendoza, A.J. (2003). Diarrhea and ARI in rural areas in Bangladesh. Southeast Asian Journal of Tropical Medicine and Public Health 34: 337-342.

Samal, S.K., Khuntia, H.K., Nanda, P.K., Satapathy, C.S., Nayak, S.R., Sarangi, A.K., Sahoo, N., Pattnaik, S.K., Chhotray, G.P and Pal, B.B. (2008). Incidence of bacterial enteropathogens among hospitalized diarrhea patients from Orissa, India. Japan Journa of Infectious Disease 61: 350-355.

Stephen, G. (2005). Childhood diarrhea in subSaharan Africa. http ://www. jhpdc.unc .edu/.

Suman, M.S.H., Alam, M.M., Pun , S.B., Khair, A., Ahmed, S and Uchida, R.Y. (2011). Prevalence of Giardia lamblia infection in children and calves in Bangladesh. Bangladesh Journal of Veterinary Medicine 9: 177-182.

Takanashi, K., Chonan, Y., Quyen, D.T., Khan, N.C., Poudel, K.C and Jimba, M. (2009). Survey of food-hygiene practices at home and childhood diarrhea in Hanoi, Vietnam. Journal of Health, Population and Nutrition 27: 602-611.

Tsehay Assefa, Hussein Mohammed, Almaz 
Abebe, Solomon Abebe and Belachew Tafesse. (1996). Cryptosporidiosis in children seen at the children's clinic of Yekatit 12 hospital, Addis Ababa. Ethiopian Medical Journal 34: 43-45.

UNICEF/WHO (2009). Diarrhea: Why children are still dying and what can be done Geneva.

Usfar, A.A., Iswarawanti, D.N., Davelyna, D and Dillon, D. (2010). Food and personal hygiene perceptions and practices among caregivers whose children have diarrhea: a qualitative study of urban mothers in Tangerang, Indonesia. Journal of Nutrition Education and Behavior 42: 33-40.

Wilunda, C and Panza, A. (2009). Factors associated with diarrhea among children less than 5 years old in Thailand: a secondary analysis of Thailand multiple indicator cluster survey 2006. Journal of Health Research 23: 17-22.

WHO (1996). Childhood diseases in Africa: fact sheets, 109:1-6. (http:www.who.int/inffs/en/ fact109.html)

\section{WHO (2000). Manual of basic techniques for a} health laboratory. Dhur Academic Publisher, Geneva.

WHO (2001). The Optimal duration of exclusive breastfeeding: Results of a WHO systematic review. Geneva.

WHO (2003). HIV and Infant Feeding-Framework for Priority Action. Geneva.World Resources Institute World Resources 1998-99: A guide to global environment. Environmental change and human health. New York: Oxford University Press.

WHO (2004). Global Burden of Disease. http:// www.who.int/healthinfo/global_burden_dis-
ease/GBD report 2004update part.

WHO (2005). The treatment of diarrhea. A manual for physicians and other senior health workers. Geneva.

Yetemwork Aleka, Seife G/egziabher, Workineh Tamir, Meseret Birhane, Agersew Alemu. (2015). Prevalence and associated risk factors of intestinal parasitic infection among under five children in University of Gondar Hospital, Gondar, northwest Ethiopia. Biomedical Research and Therapy 2:347-353.

Young, B and Briscoe, J. (1987). A case control study of the effect of environmental sanitation on diarrhea morbidity in Malawi. Journal of Epidemiology and Community Health 42: 8388. 